\title{
Increasing the Efficiency of SI-Engines by Spark-Advance Control and Water Injection
}

\author{
Lars Eriksson
}

\author{
Report \\ LiTH-R-1939 \\ ISSN 0280-3902
}





\title{
Increasing the Efficiency of SI-Engines by Spark-Advance Control and Water Injection
}

\author{
1997-04-02 \\ Lars Eriksson \\ Vehicular Systems \\ Department of Electrical Engineering \\ Linköping University, S-581 83 Linköping, Sweden \\ WWW: http://Www.vehicular.isy.liu.se \\ Email: larer@isy.liu.se
}

\begin{abstract}
By directly measuring in-cylinder parameters and adjusting the spark advance, the engine efficiency can be maximized. A feedback scheme for spark-advance control using the ionization current as sensed variable has earlier been presented. One issue is to verify that the algorithm works when the environmental conditions changes the burn rate. Humidity significantly affects the burn rate and active water injection is used to slow down the combustion giving a peak pressure position (PPP) that occurs too late. The ionization current based feedback-scheme adjusts the spark advance, and moves the PPP back to optimum. An additional result is that the engine efficiency can be increased by combining active supply of water to the combustion and the spark-advance control scheme.
\end{abstract}

Keywords: In-cylinder pressure, ionization current, peak pressure position 


\section{Contents}

1 Introduction $\quad 1$

2 Experimental setup $r$

3 Effect of water on the ionization current 4

3.1 Refining the Interpretation Algorithm . . . . . . . . . . . . . . . . . 4

4 Water injection experiments $\quad 7$

4.1 Test cycle $1 \ldots \ldots \ldots$. . . . . . . . . . . . . . 7

4.2 Test cycle $2 \ldots \ldots . \ldots \ldots$. . . . . . . . . . . . . . 7

4.3 Test cycle $3 \ldots \ldots \ldots$

5 Torque Increase $r 11$

6 Conclusions $r$ 


\section{List of Figures}

1 Left: A picture of the sprayer spraying water. Right: A schematic figure of the sprayer nozzle with the liquid spray, pressurized air, and the atomized liquid drops. . . . . . . . . . . . . . . . . . .

2 The sprayer is directed towards the intake port and throttle plate. At the lower side of the throttle plate, the spray of water can be seen as a paler shade of gray. When the picture was taken the engine ran at steady state with speed $1500 \mathrm{rpm}$ and load $50 \mathrm{Nm}$. . . . . . . . . . . . . . . .

3 Three examples of the ionization current plotted. In each plot 50 consecutive cycles is plotted. The only thing that is changed between the plots is the injection of water. . . . . . . . . . . . . . .

4 A large part of the test cycle is displayed. The spark advance controller is shut off around cycle 50 and the spark advance is held constant. The water spraying starts around cycle 250 which leads to increased PPP and decreased output torque. The spark advance controller is switched on around cycle 400, controlling PPP back to MBT leading to increased output torque. The water spraying stops around cycle 550 and the parameters asymptotically goes back to their initial conditions, when the water still in the system decreases. . . . .

5 The interesting part of the test cycle. The spark advance controller is switched off at cycle 50 and the water injection starts at cycle 250 . The controller is switched on again around cycle 500, controlling PPP to MBT which increases the output torque. . . . . . . . . . . . . . . .

6 The interesting part of the test cycle. This test is run at a lower load condition than the tests shown in Figures 4 and 5, with output torque $38 \mathrm{Nm}$. The water injection starts around cycle 150 and the spark advance controller is switched on around cycle 225. The increase in output torque when the controller is switched on can also be observed here. . . . . . . . . . . . . 


\section{Introduction}

The efficiency of a spark ignited engine can be increased by using information from the combustion to control the spark advance. The peak pressure position (PPP) of the incylinder pressure trace is a parameter that indicates how efficient the spark advance is [1]. This information about the combustion can be derived using the spark plug as sensor [2].

A hardware and software platform that implements the method, using the ionization current, has been developed [3]. It has also been verified that the algorithm can be used to control the peak pressure position [4].

This report addresses two issues. One issue is to verify that the ionization current based spark advance control algorithm can handle disturbances, so that spark advance control optimizes the efficiency when environmental disturbances change the burn duration. The test also serves as a robustness verification, so that the ionization current interpretation algorithm functions in presence of humidity and water.

Another issue is to demonstrate a new method to increase engine efficiency. The basis for the method is a combination of closed-loop spark-advance control and injection of water, i.e. actively supplying water into the engine air intake. Water injection by itself will give a decrease in engine efficiency, but in combination with the spark advance control it will be shown to increase efficiency. 


\section{Experimental setup}

To inject water into the engine a sprayer is used. The sprayer is originally a color sprayer that has a valve which delivers a liquid spray. This liquid spray is further atomized by two opposing holes that blows pressurized air on the spray. In Figure 1 a photo of the sprayer with the water spray is displayed. The figure also shows a schematic figure that displays an enlargement of the nozzle with the liquid spray and the pressurized air. The liquid is not fully atomized by the pressurized air but the droplets are made smaller. The container of the sprayer is mainly made of aluminum, while some other parts of the sprayer are made of stainless steel.
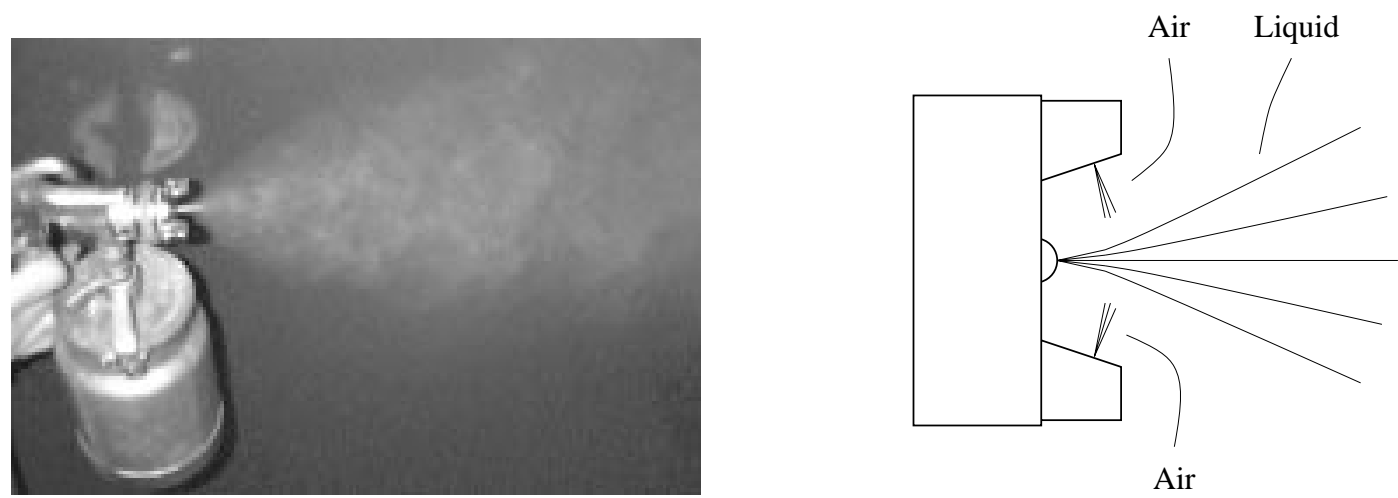

Fig. 1. Left: A picture of the sprayer spraying water. Right: A schematic figure of the sprayer nozzle with the liquid spray, pressurized air, and the atomized liquid drops.

In Figure 2 the water injection setup is shown together with the engine. As can be seen in the figure, the injection procedure is carried out by hand. The water spray is directed into the induction system towards the throttle plate. The water spray is then drawn by the lower pressure into the intake manifold.

The amount of water that is sprayed is not measured. The amount of water that was sprayed into the engine during the tests, had no audible effect on the engine during the tests. Though, there was enough water present to change the in-cylinder pressure trace so that the mean peak pressure position moved to around four to five degrees later. 


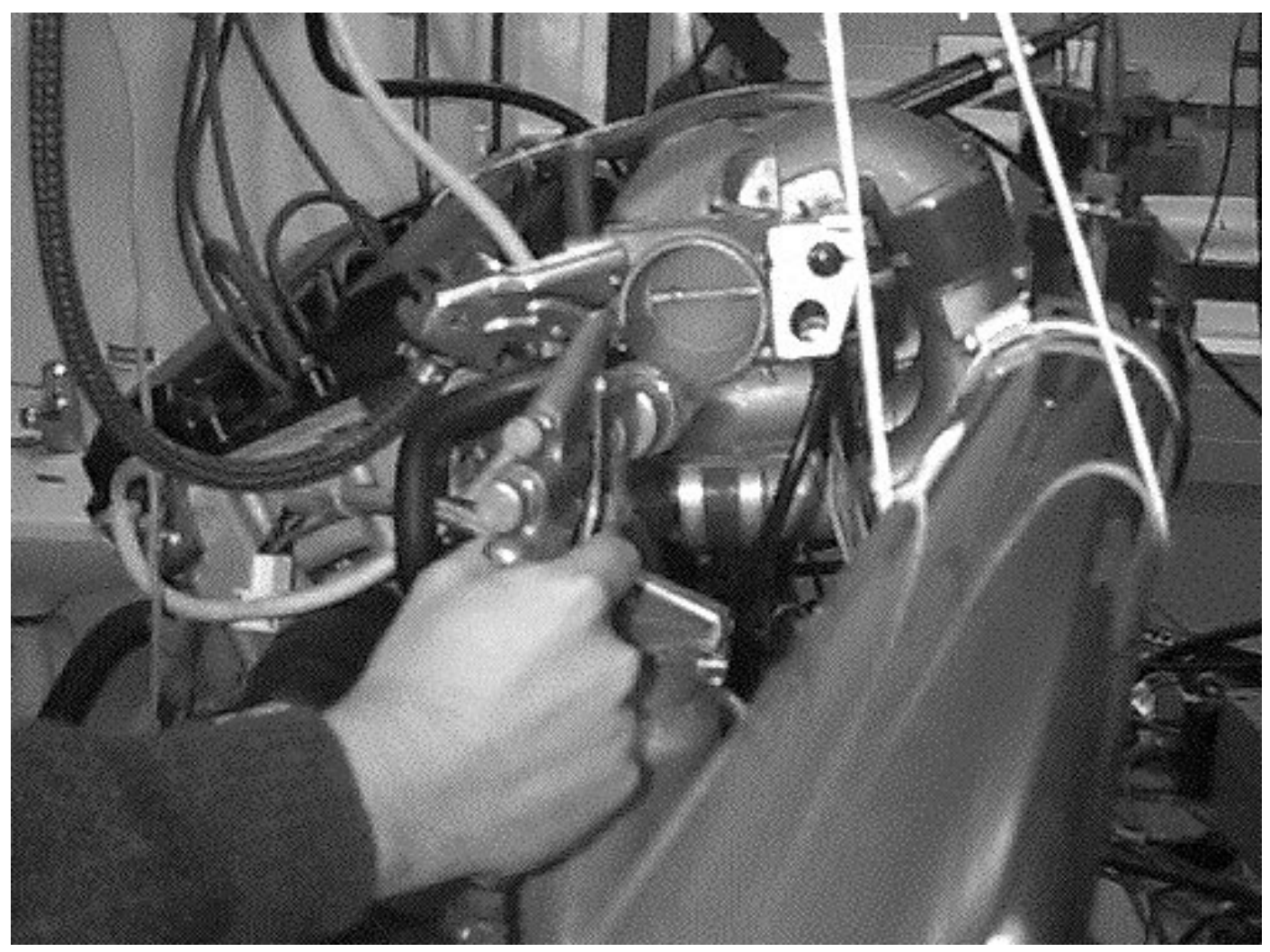

Fig. 2. The sprayer is directed towards the intake port and throttle plate. At the lower side of the throttle plate, the spray of water can be seen as a paler shade of gray. When the picture was taken the engine ran at steady state with speed $1500 \mathrm{rpm}$ and load $50 \mathrm{Nm}$. 


\section{Effect of water on the ionization current}

Injecting water into the cylinder changes several parameters that affect the ionization current. During the tests shown in Figure 3, the following parameters were held constant: spark advance, amount of fuel injected, engine speed, and throttle angle. In the figure three measurements of the ionization current are displayed. The upper plot shows when no water is injected, the middle plot distilled water, and the lower plot when normal water from the water-tap in the laboratory is injected.

The only thing that is changed between the plots in Figure 3 is the spraying of water into the induction system. Injecting water increases the amplitude of the ionization current. Normal water from the water tap gives a larger increase in amplitude than distilled. During the closed-loop tests another kind of water is injected, it is called milli-Q water and it is further purified from the distilled water. The resulting ionization current has the same amplitude and appearance as the distilled water.

The influence that water has on the amplitude and shape of the ionization current is not fully understood. The amplitude increase with ordinary tap water can come from free ions, i.e. salts, that are present in the tap water. The increase in amplitude using purified water could be guessed to come from aluminum oxides from the aluminum bottle of the sprayer.

\subsection{Refining the Interpretation Algorithm}

Water injection increases the amplitude of the post-flame phase, and the transition from the flame-front phase to the post-flame phase becomes more unclear. Without changes, the algorithm presented in [3] selects a flame front that is too small. The flame front tends to be selected to noise in the flame-front phase. Hence, the post-flame phase is selected too large and the estimated peak pressure position tends to give too small values.

This problem is overcome by using a priori knowledge of the size of the flame-front. Let $t$ be the threshold between the two phases of the ionization current, i.e. the transition from the flame-front phase to the post-flame phase. A constraint is introduced that favors $t$ to values larger than $t_{0}$. This gives the following minimization,

$$
\min _{t \geq t_{0}} J_{1}\left(\bar{\alpha}_{r}\right)
$$

which is adopted from [3]. This bound, $t \geq t_{0}$, is generally too strong since there are ionization currents with small flame fronts that has $t$ smaller $t_{0}$.

\section{Soft Bounds}

The constraint $t \geq t_{0}$ can be moved up to the criterion function and softened using e.g. the arctan function,

$$
\min _{t} J_{1}\left(\bar{\alpha}_{r}\right)+K \cdot \arctan \left(t_{0}-t\right)
$$

With this extended criterion the arctan makes the flame front larger. The parameters in $\bar{\alpha}_{r}$ are still selected based on the measured ionization current but the added soft bound makes the flame-front larger.

With the soft bound, two additional parameters, $K$ and $t_{0}$, are introduced. These parameters depend on the operating condition and have to be tuned. The parameters are tuned such that the soft bound do not have an effect on the estimation algorithm during normal conditions. A simple tuning rule for the soft constraints is to find the parameters that affect the estimation algorithm very little and then adjust $t_{0}$ to a slightly smaller value. This tuning has shown good results here. 

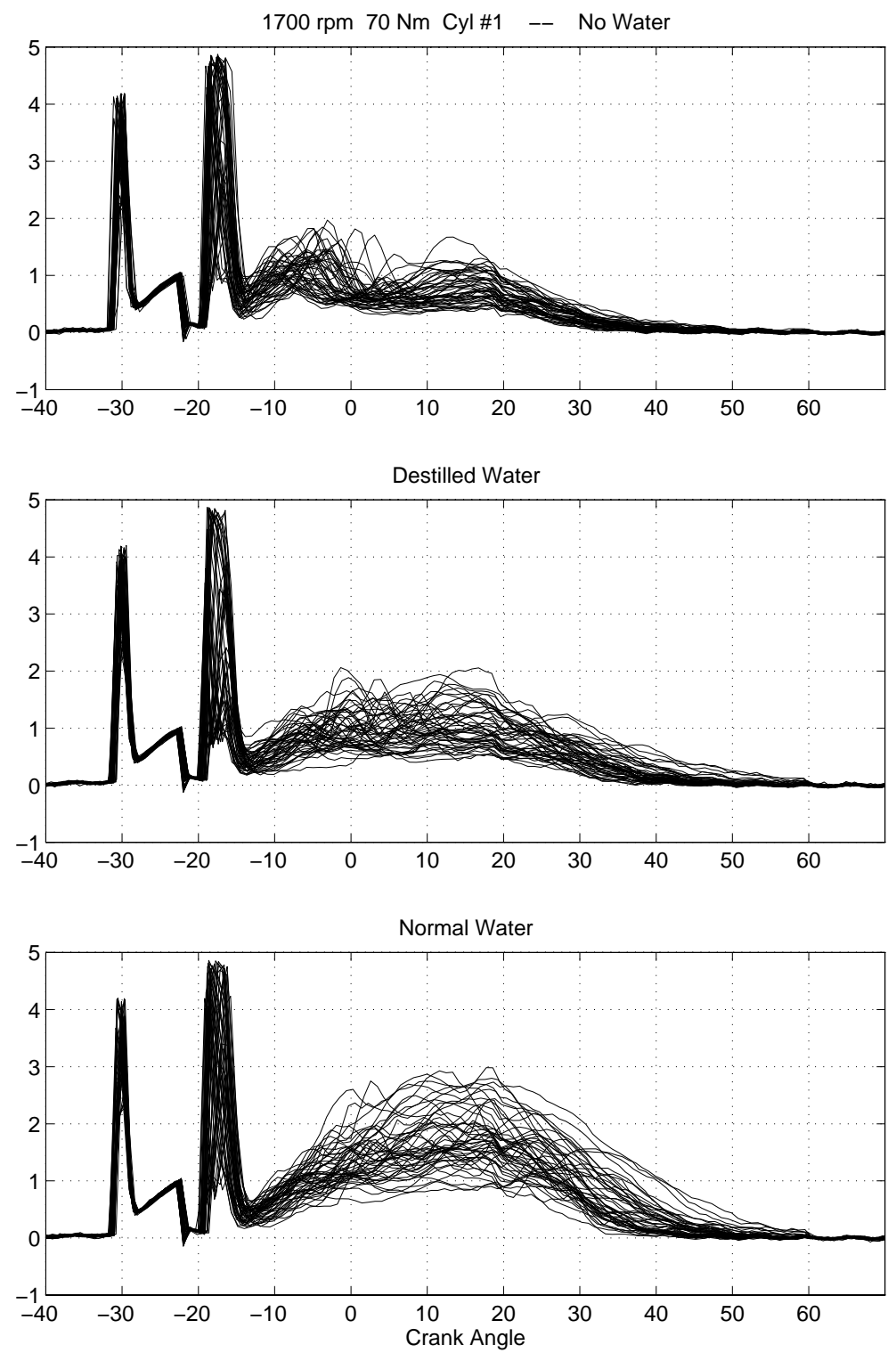

Fig. 3. Three examples of the ionization current plotted. In each plot 50 consecutive cycles is plotted. The only thing that is changed between the plots is the injection of water. 
One way to view the soft bound is that it supports the interpretation algorithm, by including knowledge of the characteristics of the ionization current. 


\section{$4 \quad$ Water injection experiments}

During all test cycles in the Figures 4, 5, and 6, the throttle angle and the injection time are held constant, the engine speed is also held constant by a controller for the dynamometer. The engine is running at steady state and the $\mathrm{A} / \mathrm{F}$ ratio is tuned to $\lambda=1$ before the test cycle starts. Then the injection time is held constant during the test cycle.

\subsection{Test cycle 1}

Figure 4 shows a large part of the test cycle. The speed and load condition is $1500 \mathrm{rpm}$ and $55 \mathrm{Nm}$. Initially in the test cycle, the spark advance controller is running and the controller changes the spark advance controlling the peak pressure position close to MBT, i.e. $16^{\circ}-17^{\circ}$ after TDC. The ionization current is used as input to the controller, and the in-cylinder pressure is only used for validation. Around cycle number 100 the spark advance controller is turned off and the controller holds the present value. Around cycle 250 the spraying of water is started. Note that the peak pressure position is moved to a position $4^{\circ}$ later and that the output torque decreases. Around cycle 400 the spark advance controller is turned on again and it controls the peak pressure position back to its optimal value. The controller needs to change the spark advance with around $5^{\circ}$ to get back to the optimal position.

Around cycle 550 the water spraying stops. This can be seen in the figure when the change in spark advance starts to decrease. When the water spraying stops it takes a while before all water has passed through the system, in the figure it can be seen that the states asymptotically goes back to their initial conditions.

The signals: PPP, output torque, manifold pressure, and lambda has been filtered off-line with the non-causal filtering procedure with zero phase shift, this procedure is included in the signal processing toolbox in Matlab. The filter that is used is a Butterworth filter with order 3 , and with normalized cut-off frequency at 0.3 .

\subsection{Test cycle 2}

Another test cycle is shown in Figure 5, where the speed and load conditions also are $1500 \mathrm{rpm}$ and $55 \mathrm{Nm}$. Only the part of the test cycle showing the water spraying and the controller switching on and off is displayed in the figure. The test cycle that has been run is the same as described above, but in this test the reference value of the controller is changed one degree to $17^{\circ}$ after TDC.

At cycle 50 the controller is turned off and the spark advance is held at its present value. At cycle 250 the water spraying is started, and two things can be noted at this point. Firstly, which is the most important point is that the PPP moves 4 degrees. Secondly, that the actual spark advance changes in the wrong direction due to the change in intake pressure. When the controller is turned off, the spark advance can be viewed as a pre-calibrated schedule with a spark advance close to MBT. The parameters that affect the spark advance is then the engine speed and the manifold pressure. Note that the calibrated scheme changes the spark advance in the wrong direction, since increased manifold pressure indicates higher load and therefore less spark advance.

The spark advance controller is switched on again at cycle 500. The PPP is controlled to $17^{\circ}$ ATDC by using information from the ionization current. Note that the output torque increases when the controller is switched on, since the spark advance goes back to a point close to optimum. 

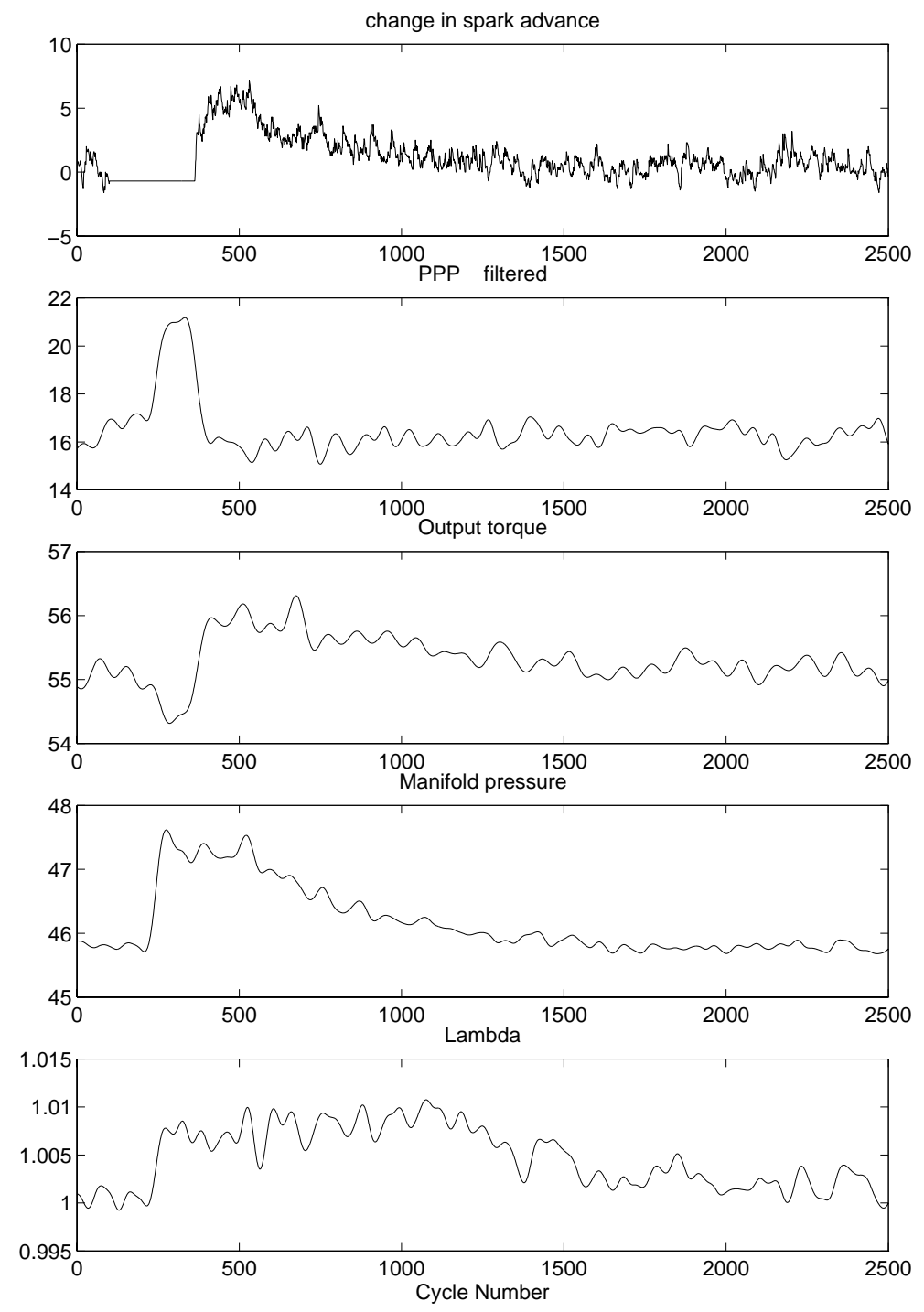

Fig. 4. A large part of the test cycle is displayed. The spark advance controller is shut off around cycle 50 and the spark advance is held constant. The water spraying starts around cycle 250 which leads to increased PPP and decreased output torque. The spark advance controller is switched on around cycle 400, controlling PPP back to MBT leading to increased output torque. The water spraying stops around cycle 550 and the parameters asymptotically goes back to their initial conditions, when the water still in the system decreases. 

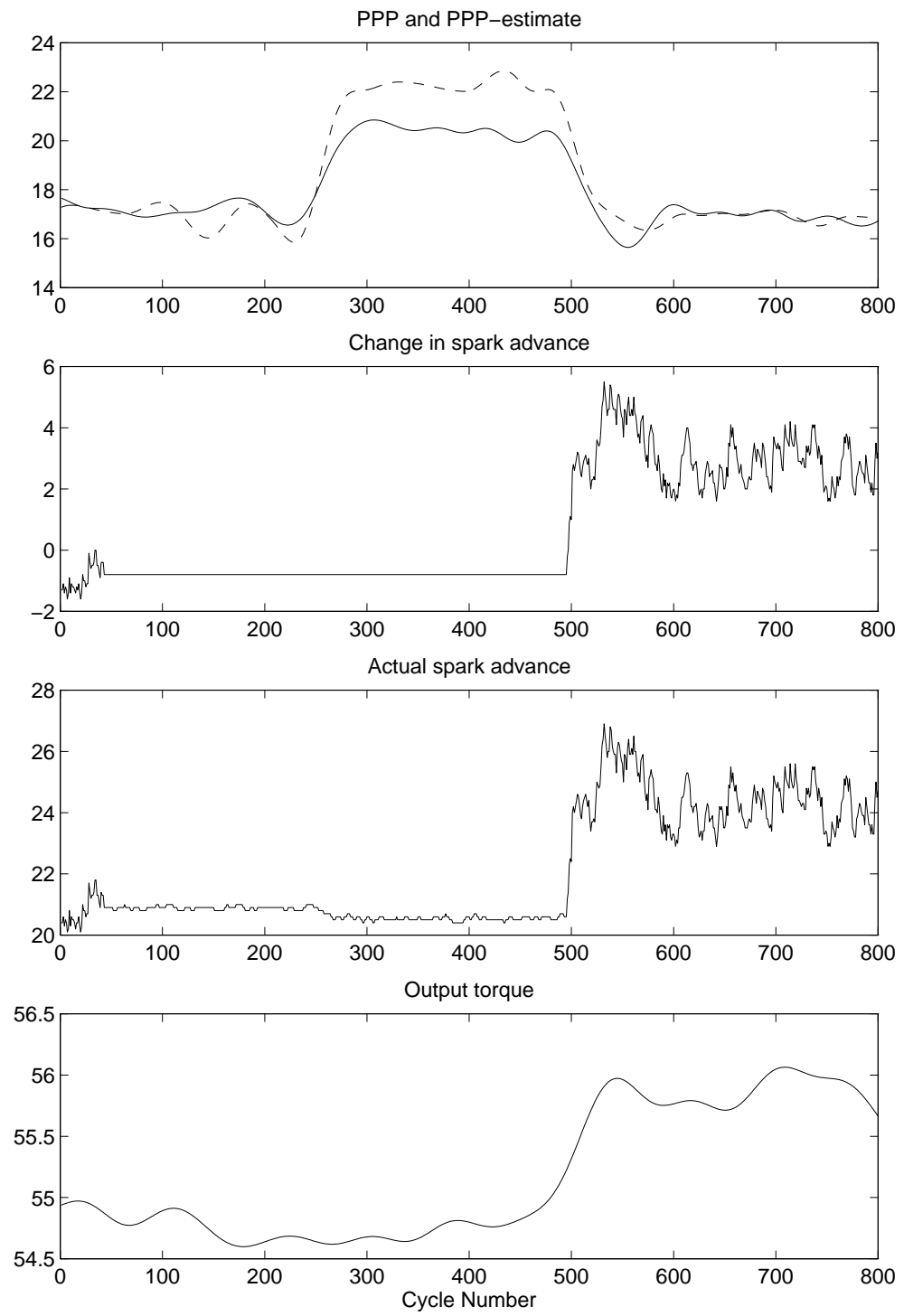

Fig. 5. The interesting part of the test cycle. The spark advance controller is switched off at cycle 50 and the water injection starts at cycle 250. The controller is switched on again around cycle 500, controlling PPP to MBT which increases the output torque. 


\subsection{Test cycle 3}

In Figure 6, a test cycle with a different load condition is displayed. The operating condition is $1500 \mathrm{rpm}$ and $38 \mathrm{Nm}$, and the desired peak pressure position is $16^{\circ}$ after TDC. The same effect as in Figure 5 can be seen: the presence of water moves the peak pressure position, and the controller compensates for the changed environmental condition and increases the output torque.
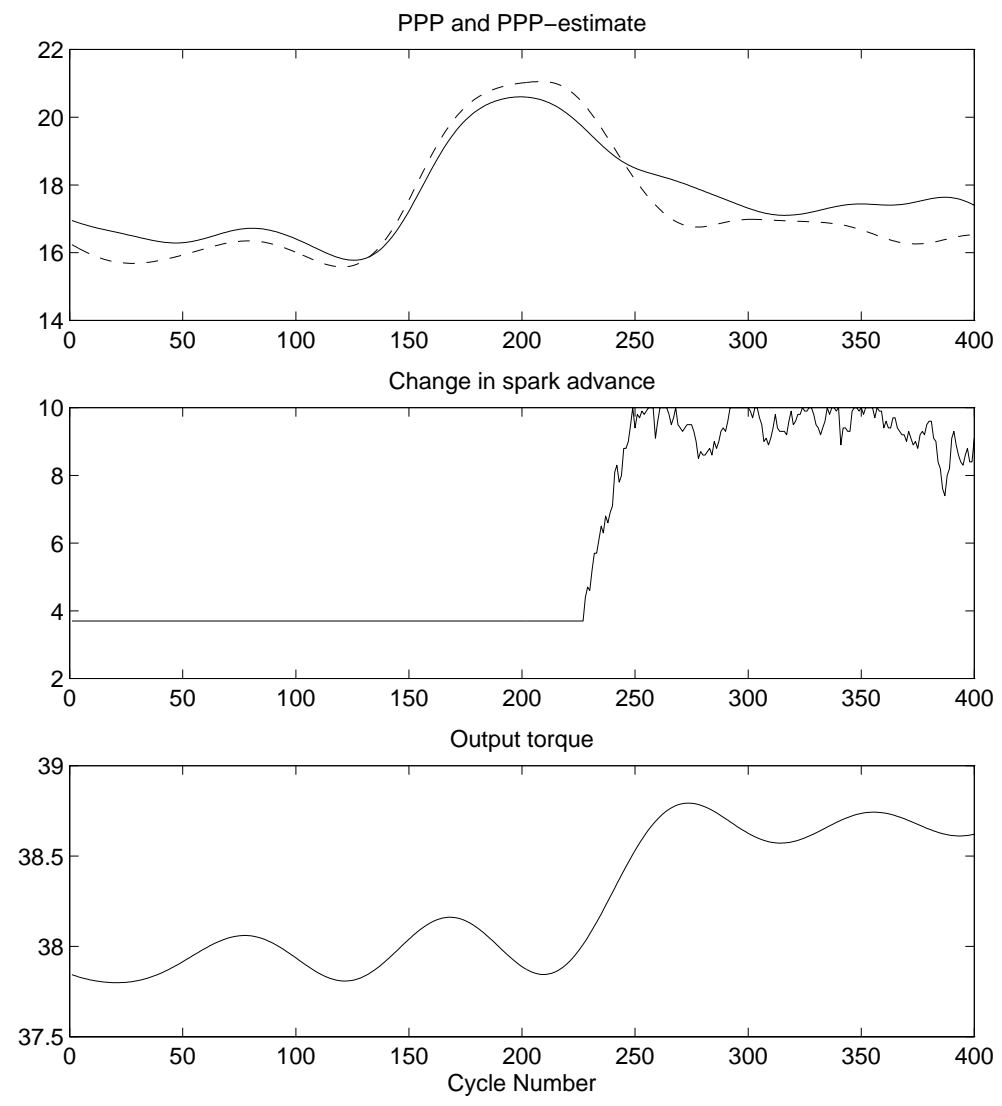

Fig. 6. The interesting part of the test cycle. This test is run at a lower load condition than the tests shown in Figures 4 and 5, with output torque $38 \mathrm{Nm}$. The water injection starts around cycle 150 and the spark advance controller is switched on around cycle 225. The increase in output torque when the controller is switched on can also be observed here. 


\section{Torque Increase}

In all three figures the start of the controller increases the output torque with $1.5-3 \%$. The increase in power comes from different sources. In Figure 4 it is shown that the A/F ratio increases which increases the fuel conversion efficiency, and since the amount of fuel is constant this implies an increase in output torque. A $1 \%$ increase in $\mathrm{A} / \mathrm{F}$ can change the fuel conversion efficiency with $0.4 \%$ (this increase is derived from Heywood [5] page 182).

Figure 4 also shows that the manifold pressure increases with $2 \%$. Increasing the manifold pressure lowers the losses to the pumping work, indicating that the output torque should increase. In the figure it can be seen that the manifold pressure does not drop directly when the spraying stops, instead it slowly decreases as the water evaporates. Hence, it is the presence of water in the intake manifold that raises the pressure and not that the sprayer blows air and water on the throttle plate.

The presence of water also cools the air which, for the same pressure, make the air density higher. The lower temperature also have a favorable influence on the thermodynamic cycle and increases the output torque.

Important to note is that to get the increase in output torque with water injection, it is necessary to change the spark advance to gain the benefits. In Figure 4 the output torque actually decreases when the water is injected, the increase in efficiency comes when the spark advance controller is switched on. With a spark advance control based on feedback from the combustion it is possible to hold the spark timing close to optimum under a variety of changing conditions, and increase the efficiency. 


\section{Conclusions}

Spark advance control utilizing the spark plug as sensor has been shown to increase the efficiency of the engine. Water has been sprayed into the manifold as a disturbance to the combustion. The spark control algorithm based on the ionization current compensates for the changes in burn rate of the combustion, and the spark advance for the engine is controlled close to optimum using feedback.

Furthermore, the results give a new method to actively increase engine efficiency by combining water injection with ionization current based spark advance control.

\section{References}

[1] M. Hubbard, P. D. Dobson, and J. D. Powell. Closed loop control of spark advance using cylinder pressure sensor. Journal of Dynamic Systems, Measurement and Control, pages 414-420, december 1976.

[2] Lars Eriksson, Lars Nielsen, and Jan Nytomt. Ignition control by ionization current interpretation. SAE SP-1149, (SAE paper No. 960045):73-79, 1996.

[3] Lars Eriksson. A real-time platform for spark advance control. Technical Report LiTHR-1938, ISSN 1400-3902, Department of Electrical Engineering, 1997.

[4] Lars Eriksson, Lars Nielsen, and Mikael Glavenius. Closed loop ignition control by ionization current interpretation. SAE SP-1236, (SAE paper No. 970854):159-166, 1997.

[5] J. B. Heywood. Internal Combustion Engine Fundamentals. McGraw-Hill series in mechanical engineering. McGraw-Hill, 1988. 